\title{
Digital and organizational transformation of the educational process
}

\author{
Tatyana Leybert \\ Accounting and audit chair \\ Ufa State Petroleum Technological \\ University \\ Ufa, Russia \\ lejjbert@mail.ru \\ 0000-0001-9009-5557
}

\author{
Elvira Khalikova \\ Accounting and audit chair \\ Ufa State Petroleum Technological \\ University \\ Ufa, Russia \\ ydacha6@yandex.ru \\ 0000-0003-1197-5420
}

\begin{abstract}
The digital transformation of the Russian economy is becoming one of the areas of strategic development of companies. In this regard, approaches to assessing the knowledge and skills that a modern employee must meet are changing. In this regard, there is a need for the formation of a new model of human capital, which reflects both the development of traditional competencies and the formation of new, so-called digital competencies. The formation and implementation of a new model of human capital involves the development of a system for the development of human capital, which should be considered as a comprehensive concept of personnel management. Structuring the professional and digital skills of the personnel that make up the human capital of companies depends on their digital literacy, which is based on digital competencies. As a result, for the successful formation of a digital space and the implementation of a new model of human capital in it, a digital and organizational transformation of the educational process is necessary, involving a change in the content of the main educational programs, suggesting the introduction of a model of digital competencies in the context of lifelong learning.

The article shows that in modern companies, in connection with the need to make "digital" decisions on the management of individual business processes, new demands are made on human capital. In this regard, the necessity of developing a new model of human capital in the context of digital transformation is substantiated, the implementation of which is possible in the conditions of digital and organizational transformation of the educational system.
\end{abstract}

A model of human capital developed by the authors in the context of digital transformation is presented, which defines novelties for the development of human capital and its transformation based on a competency-based approach. A model of the student's digital competencies structure is proposed, which allows achieving the full range of organizational transformation of education during the transition to digital education. The authors propose the formation of a model of digital and organizational transformation of the educational process, provides for the methodological support of the educational process, the formation of the trajectory of development of traditional and new digital competencies, the development of technologies for studying the disciplines of the educational program, the presence of a dispersed schedule of the educational process and learning outcomes. The article clarifies the concept of "digital competencies", provides a meaningful description of universal, general professional and professional competencies, which in digital education reflect the demands of the labor market in one or more related professional fields in terms of the future specialist's knowledge of relevant digital skills and their application in professional activities. Also, the authors of the article cited the phased formation of competencies in the formation of the trajectory of development of traditional and new (digital) competencies.

Keywords-Digital transformation, human capital, educational process, digital competencies, knowledge management, digital education

\section{INTRODUCTION}

In the current economic environment characterized by increased competition, complexity of production and innovative development, increasing importance is attached to issues related to the formation of a new model of human capital, which can be represented as a combination of knowledge, competencies, and experience possessed by individuals and which make them economically useful, efficient, effective.

The observed structural changes in companies placing greater demands on the level of competence, professionalism and qualification of human capital, is the intellectual embodiment of the company's staff. At the same time there is a growing need for structuring the professional skills of employees for effective integration in the functioning of the technological, production, service, economic, informational, social business processes. In this regard, there is a need to develop tools to ensure conformity of results of core business processes, resources providing processes by the amount and direction for the management of human capital in the system of external and internal conditions.

For example, the ongoing innovation and digitalization processes in oil companies significantly complicate the process of hydrocarbon production, hydrocarbon processing and marketing of refined products: "digital fields", "digital plants" appear. There is a need to make "digital" decisions on the management of individual business processes in the oil companies. These processes gradually impose new requirements on human capital and make it necessary to increase the share of intellectual labor and determine the growing role of knowledge, competencies and skills of workers as one of the leading factors of production in modern conditions.

This is reflected in the formation of the target system for the integrated development of human capital of companies, including the development of traditional competencies vocational, corporate, leadership, and the formation of new competencies that are adequate to the changing needs of the 
outside world. Undoubtedly, the new competencies include digital competencies of employees.

To implement a new model of human capital in the context of digital transformation, a digital and organizational transformation of the educational system is needed, affecting both educational programs in terms of introducing a model of digital competencies in the context of lifelong learning, and the role of teachers in teaching digital skills. Only the introduction of advanced educational technologies and innovative models of education with elements of digitalization will allow us to create the image of an employee of the future that meets the strategic goals of the company's development and sets the trends for the implementation of the directions of digital transformation of the company's economy.

\section{PROBlem Statement}

Scientific literature $[1,2]$, the sites of various information resources, with different definitions of digitalization, the digital economy and the related formulations of the substantial development of human capital. If the digital economy is seen as the economy, mediated virtuality, augmented reality, or how the economy formalized Internet resources, digital competence, which should have a human capital "the future," presented as a person's ability to work with data in digital form and to use digital technologies in all business processes, to manage the process of introducing digital technologies in all activities [3, 4]. This implies that digital competence represents the ability to manage information technology processes using information and communication technologies. In our opinion, based on digital competences are digital skills, aimed at the development of human capital in creating and sharing digital content using digital devices and communication applications.

The development of human capital can be interpreted in different ways: from the point of view of the use of it tools that contribute to the development of human capital, with the position of the Department of human resources, where the link is the staff that performs complex tasks for the development of human capital as well as the position of merger of the two above-mentioned positions.

It is customary to single out the following tools for the development of human capital: knowledge base; community of practice; lessons learned; social networks of experts; expert database; bank of ideas; service of questions and answers; seminars and conferences; mentoring. The development of human capital can be interpreted in different ways: from the point of view of using IT tools that contribute to the development of human capital, from the position of the human resources management department, where the liaison is staff that performs a set of tasks for the development of human capital, as well as from the point of view of merger the two above positions.

Imagine the case of a Russian oil company, reflecting the practice of developing human capital, which contributes to increasing competitive advantages. PJSC Gazprom Neft is a vertically integrated oil company whose main activities are exploration and development of oil and gas fields, oil refining, as well as the production and marketing of petroleum products.

Figure 1 shows the architecture of human capital development in the oil company PJSC Gazprom Neft.
The analysis revealed trends in the development of human capital in the oil sector of the Russian economy, these are: complexity of use, weak adoption of innovations that are not related to production / technological processes, the beginning of the emergence of an active policy of knowledge exchange, movement towards creating a flexible system of human capital development.

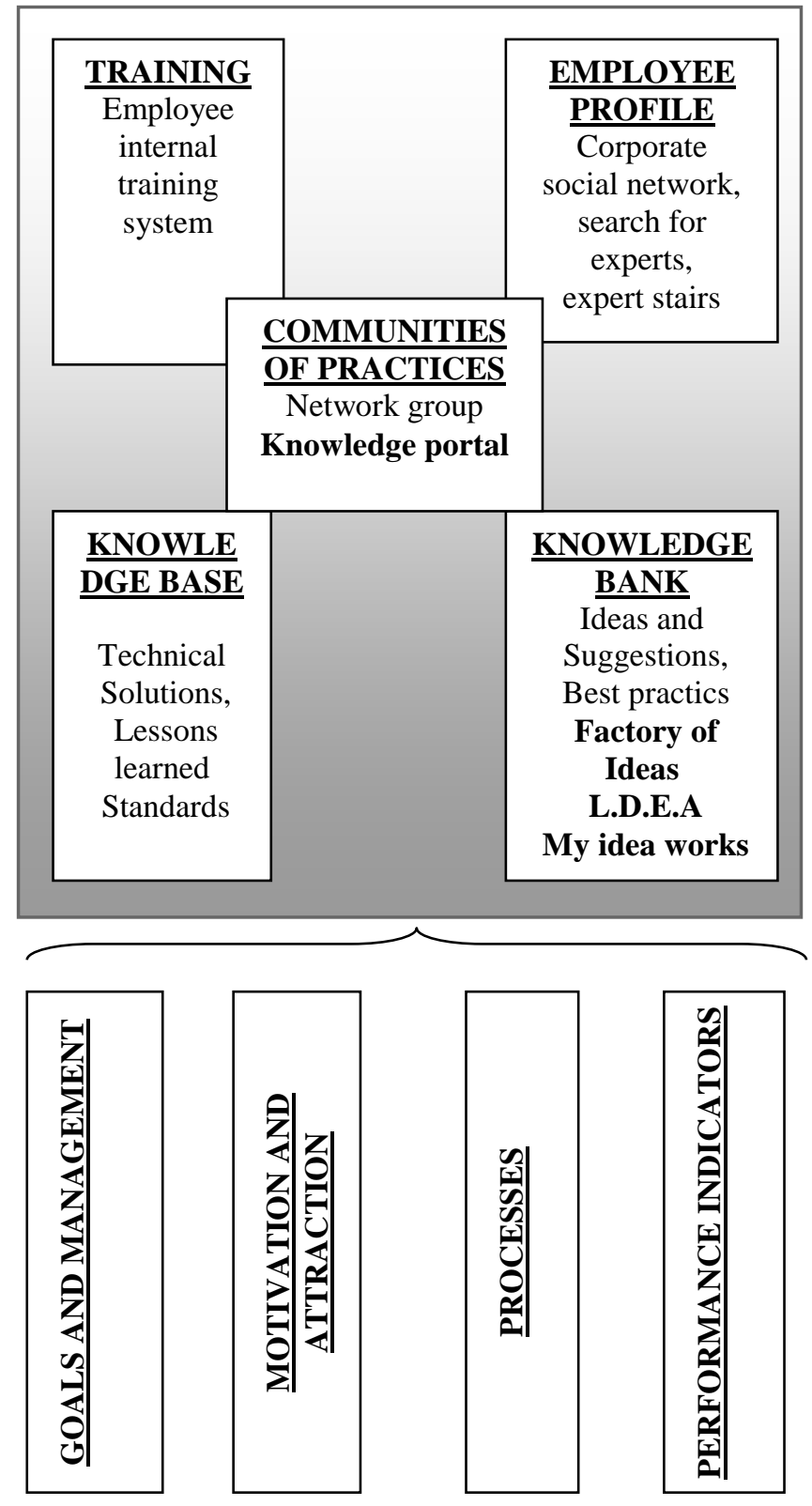

Fig.1. Architecture of human capital development in the oil company PJSC Gazprom Neft

\section{METHODOLOGY}

To improve the efficiency of human capital management of the company in the interests of its new developments it is useful to define a comprehensive system of human capital development, which will provide planning and monitoring of all processes in the life cycle of human capital and the interaction of the structural divisions of the company to implement these processes. The main purpose of the implementation of the system of human capital development 
development of a system for management of information processes of human capital development, major internal and external factors influencing planning of expenditures, etc.

In our opinion, the system of human capital development should be viewed as an integrated concept of personnel management, which supports the process of efficient decision-making on the alternative basis, and allows monitoring of effectiveness of management and evaluation of the development of human capital, measured by indicators similar to the parameters of movement, speed, accuracy, standardization situations, and unambiguous behaviour for a long period of certainty, finality, singleness of action, cost of material and personal costs.

A comprehensive system of human capital development involves the specification of its main functions. Thus the main functions of human capital development include:

1) planning activities of the staff; 2) take into account indicators of controlling staff on the basis of evaluation criteria; 3) analysis of development of the personnel and deviations of indicators obtained from established values; 4) informational-analytical ensuring of the functioning of personnel; 5) monitoring the external environment; 6) coordination between strategy, policy and system of human capital management.

For the formation and accumulation of human capital need to invest various resources in its development (material, informational, financial, natural, spiritual), as well as to perform any actions and functions on its formation and accumulation. Investments in human capital are the resources that generate new skills, accumulating new knowledge, information and experience in the preparation and operation personnel, that is, the ability to work. In other words, investment is the cost of creating human capital and the human capital, in all its components - is the result of the process of its formation and accumulation.

Each component of human capital requires a certain cost, investments, activities. Therefore, each component of human capital should correspond to your type of investment.

The prospects for effective investment in human capital depends on creating a new paradigm of education that promotes the formation of new approaches to teaching aimed at developing students ' digital skills to ensure their successful existence in the digital environment in the future. That is, the educational environment should form the basic digital skills in students, allowing them to access your files, devices, online services and applications. Corporate environment he gets in the face of so-called "digital" employees for the formation of a new model of human capital in companies. Development of staff in the new model, human capital will generate derivatives of employees digital skills to use digital technology in the workplace. Derivatives digital skills are associated with skills and abilities to use digital technology for high-performance and high-tech jobs. Human capital, endowed with such skills, is the difference between digital skills digital services, online applications, information portals, which determines its ability to implement them in practice and get a positive result.

The new model of human capital in the context of digital transformation determines the image of an employee with digital literacy, which is based on digital competencies. Digital literacy is determined by the set of knowledge and skills necessary for building and implementing effective business models that are adequate to the directions of the digital environment and that allow using digital technologies and Internet resources with the help of infrastructure elements of the digital economy. Digital literacy includes the personal, technical, and intellectual, digital skills that are required to exist in a digital environment.

A new model of human capital in the context of digital transformation can be represented as a set of areas of competence and skills that allow company employees to build relationships in conjunction with complex digital systems covering a set of companies, technologies (information, automated, intelligent), people. All this will lead to the emergence of new requirements for existing jobs, to the emergence of new professions, to the emergence of specialists with the necessary qualifications in the IT field, which, ultimately, will lead to the buildup of highperformance jobs that can implement projects of digital transformation of companies.

An illustration of a new model of human capital in a digital transformation with the example of an oil company is shown in Figure 2.

The developed model of human capital in the context of digital transformation defines novelties for the development of human capital, its transformation on the basis of a competency-based approach, and represents a single target system for the comprehensive development of human capital, characterized by a list of digital competencies within the field of digital competencies, combined with indicators of their manifestations in professional activity, creates conditions for harmonizing the criteria for the selection and assessment of personnel with company goals for hiring and promotion of employees, the competence of which to the greatest extent meet the current and strategic needs of the company, for the development of priority directions of development of digital professional staff and the development of effective measures for the training of digital technology, the most valuable employees. 

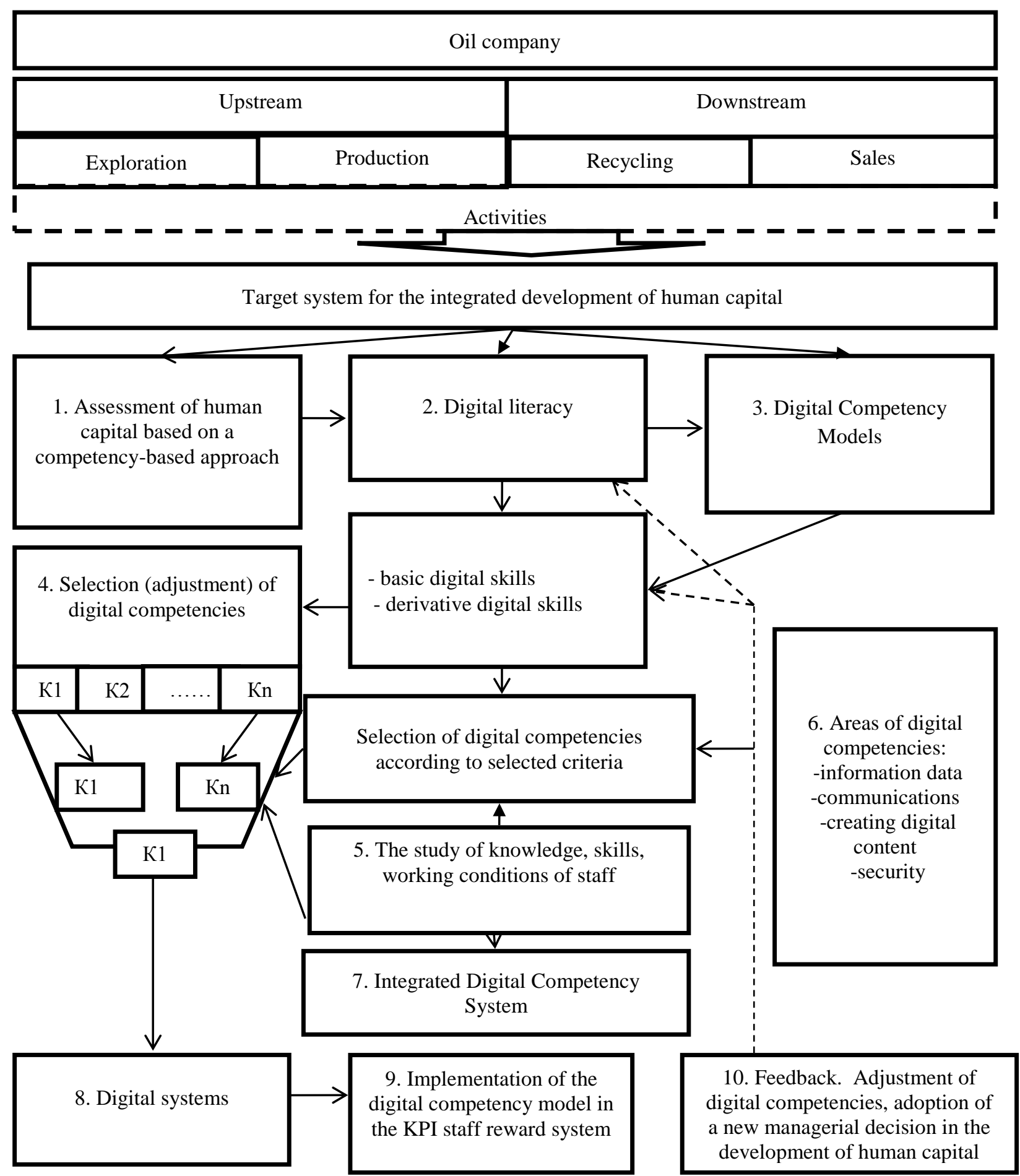

Fig. 2. A new model of human capital in the context of digital transformation (for example, an oil company)

To determine the possibilities of realizing human capital in the context of digital transformation with the goal of developing human capital, it is necessary to solve the following problems:

-determining the image of an employee with digital literacy;

-forming a model of digital competencies;

-development of a list of digital competencies in accordance with the areas of digital competencies; -determining and evaluating the digital skills of company employees

- Formation of a corporate governance system as a tool for balancing digital and professional skills;

-determining the development path of a future specialist with digital literacy, digital competencies and digital skills;

-development of innovative education models and the introduction of advanced educational technologies; 
-consider the practical aspects of introducing controlling technologies in the development of human capital in oil companies.

Digital competencies are becoming the new result of training in basic education programs. This is facilitated by the formation of the information society and the determination of the targets of the digital economy. Digital education will contribute to the development of digital culture for students. As competencies of the digital culture, professional competencies, general professional competencies and universal competencies will be used.

In the digital economy, the current competencies of the future specialist will be formed through individual educational development paths. The model of the student's digital competencies structure can be represented in Fig. 3.

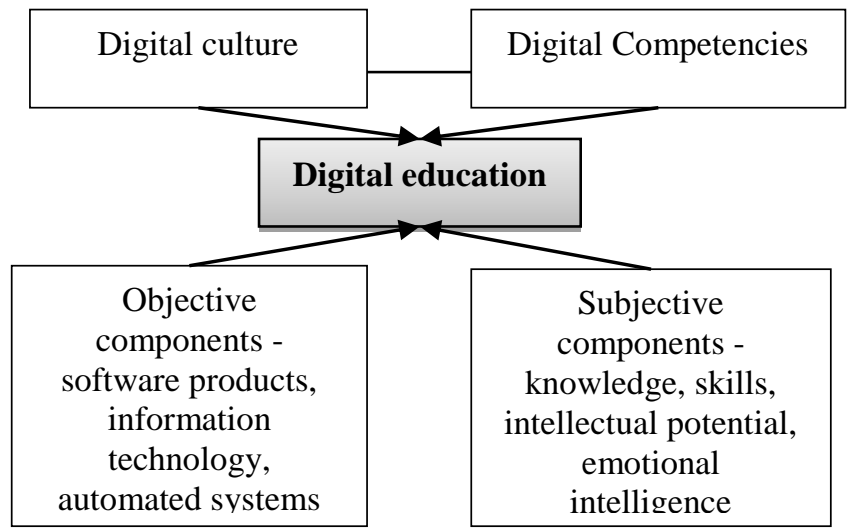

Fig. 3. The model of the structure of the student's digital competencies

Thus, a full range of organizational transformation of education is achieved in the transition to digital education from the formation of the basic foundations of digital culture and its implementation in the future in professional activity to the determination of the composition of functions and tasks solved by using objective and subjective components of the educational process, including models, forms of cognition, knowledge, skills, competencies, intellectual potential, emotional intelligence.

In the process of digital and organizational transformation, digital competencies pass through the prism of universal, general professional and professional competencies.

Universal competencies in digital education reflect the expectations of the modern information society regarding the positioning of a future specialist in it, in the person of a graduate of the main higher education educational program of the appropriate level and orientation of the educational program, its acceptable readiness for self-realization, selfdevelopment, responsible use of digital technologies in training, and digital cooperation. Universal competencies in digital education will be formed by studying the basic foundations of digital culture, data storage and processing models, computer programming and modeling.
General professional competence in digital education reflect the needs of the labor market in one or more related professional areas in terms of ownership of the future specialist in the person of a graduate of the basic educational program of higher education of corresponding level and direction of custom digital skills and their application in professional work, digital competence, which are necessary for existence in the digital world. General professional competence in digital education will be formed to study digital culture in professional activity, applied artificial intelligence, models of data processing and analysis, strategies of digital business and electronic Commerce technologies.

Professional competence in digital education reflect the needs of the labor market in terms of ownership of the future specialist in the person of a graduate of the basic educational program of higher education of corresponding level and direction of special professional digital skills; it required the readiness to perform complex professional tasks in the digital environment within a particular profession, including its possible willingness to carry out job functions with the appropriate level of qualification, underlying the high-tech professions, and established a professional standard for the corresponding type of professional activity.

Professional competencies in digital education will be formed by studying the analysis of unstructured data (Big Data) in the digital economy, intelligent information technologies in various types of professional activities, designing information systems in the digital economy, storing assets using blockchain technologies, cloud technologies in the digital economy, developing databases and a databank in information systems, information protection and electronic digital signature, relevant issues of support and information security in the digital economy, methods of using ERP-systems in the digital economy.

\section{RESULT}

The results of scientific research in the field of digital and organizational transformation of the educational process the authors propose the formation of a model of digital and organizational transformation of the educational process envisages the presence of methodical support of educational process, the formation of the trajectory of the development of traditional and new digital competences, the development of technologies of studying of disciplines of the educational program, the presence of a dispersed schedule of the educational process and learning outcomes, characterized by the formation of the corresponding competences (universal, all-professional, professional).

Methodological support of digital and organizational transformation of the educational process will be supported by the use of electronic resources of companies, software products, master classes and business games from leading specialists of the companies (Fig. 4). 


\begin{tabular}{|c|c|c|}
\hline $\begin{array}{l}\text { Electronic } \\
\text { resources of } \\
\text { companies }\end{array}$ & $\begin{array}{c}\text { Software } \\
\text { Products } \\
\text { (ERP) }\end{array}$ & $\begin{array}{l}\text { Master classes and } \\
\text { business games } \\
\text { from leading } \\
\text { experts of }\end{array}$ \\
\hline $\begin{array}{c}\text { Electronic } \\
\text { manuals, } \\
\text { teaching } \\
\text { materials, } \\
\text { videos (video } \\
\text { clips and } \\
\text { reports) about } \\
\text { the company's } \\
\text { information } \\
\text { technology } \\
\text { platform, } \\
\text { methods and } \\
\text { technologies } \\
\text { for the } \\
\text { formation and } \\
\text { processing of } \\
\text { information; } \\
\text { managerial } \\
\text { decision } \\
\text { making }\end{array}$ & $\begin{array}{l}\text { The } \\
\text { educational } \\
\text { version of the } \\
\text { corporate } \\
\text { information } \\
\text { system, based } \\
\text { on the ERP } \\
\text { methodology, } \\
\text { is designed to } \\
\text { develop } \\
\text { practical } \\
\text { competencies } \\
\text { in the field of } \\
\text { working with } \\
\text { decision } \\
\text { support } \\
\text { systems in the } \\
\text { modern digital } \\
\text { economy }\end{array}$ & $\begin{array}{c}\text { Active } \\
\text { participation of } \\
\text { specialists in } \\
\text { the field of } \\
\text { development } \\
\text { and operation } \\
\text { of decision } \\
\text { support systems } \\
\text { for companies } \\
\text { in the } \\
\text { educational } \\
\text { process, the use } \\
\text { of an interactive } \\
\text { form of training } \\
\text { (master classes, } \\
\text { business } \\
\text { games) }\end{array}$ \\
\hline
\end{tabular}

Fig. 4. Methodological support for the digital and organizational transformation of the educational process
The trajectory of the development of traditional and new competencies includes two stages.

The first stage is the formation of basic competencies in the framework of expanding the knowledge and skills acquired in the process of the main educational program. The list of key competencies at this stage is established on the basis of an analysis of the structure of the specialist's activities in the digital environment: Motives - goals - actions (external) - self-development (internal actions and the subject result of the activity) - subject (objective result) - long-term results (consequences and effects of the activity). A schematic representation of the first stage in the formation of basic digital competencies is presented in Figure 5.

Stage I: Formation of basic competencies as part of the expansion of knowledge and skills acquired in the process of the main educational program.

The list of key competencies is established on the basis of an analysis of the structure of the specialist's activities in the digital environment:

Motives - goals - actions (external) - self-development (internal actions and the subject result of activity) - subject (objective result) - long-term results (consequences and effects of the activity)

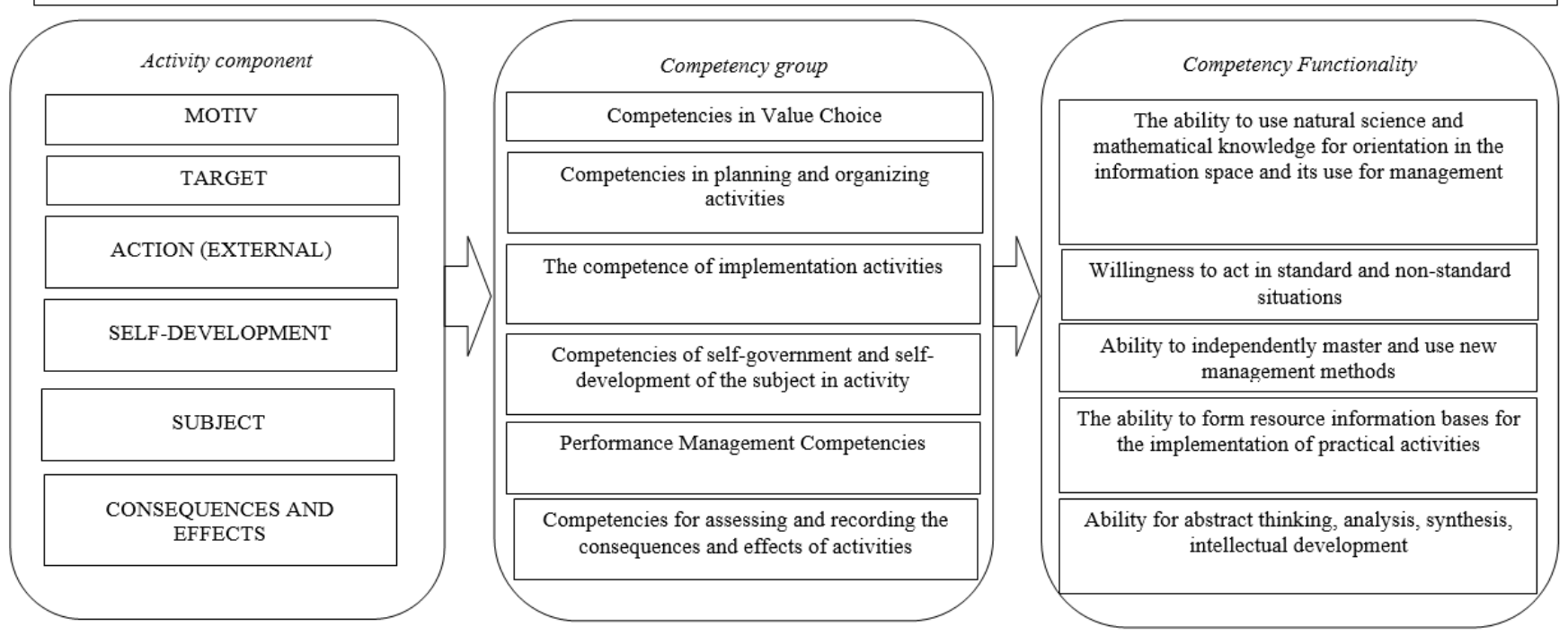

Fig. 5. The first stage of the formation of competencies in the formation of the development path of traditional and new (digital) competencies

The second stage is the formation of managerial competencies in the digital economy. A schematic representation of managerial competencies is presented in Figure 6. 


\begin{tabular}{|c|c|}
\hline \multicolumn{2}{|r|}{ Stage II: Formation of management competencies in the digital economy } \\
\hline COMPETENCE GROUP & COMPETENCE FUNCTIONAL \\
\hline \multirow{4}{*}{$\begin{array}{l}\text { Systematic knowledge of the digital } \\
\text { economy }\end{array}$} & $\begin{array}{l}\text { Immersion of managers and specialists in the process of obtaining systematic knowledge about the digital economy, the nature of digital } \\
\text { technologies and system transformations at the micro, meso, macro levels and global digitalization }\end{array}$ \\
\hline & Understanding the ongoing changes from a position of a systems approach \\
\hline & Ability to make effective decisions in conditions when it is impossible to predict the emergence of many new processes \\
\hline & Prioritization of the launch of certain transformations based on the assessment of qualitative changes in the company \\
\hline & 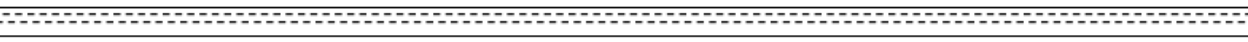 \\
\hline & Strategic management. Ecosystem Management Approach \\
\hline \multirow{3}{*}{$\begin{array}{c}\text { Hybrid Transdisciplinary Management } \\
\text { Competencies ("Technology }+ \\
\text { Economics") }\end{array}$} & Identification of transformation zones and rationale for digitalization \\
\hline & Coordination of strategic documents taking into account the stage of development of the digital environment \\
\hline & Search for ways to increase the profitability and efficiency of the company \\
\hline & Creation and management of innovative space \\
\hline & 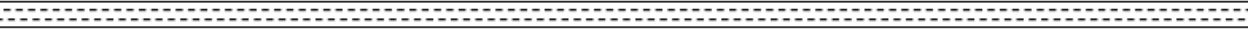 \\
\hline \multirow{2}{*}{$\begin{array}{l}\text { Management competencies for the } \\
\text { development of projects and }\end{array}$} & Identification of areas of cooperation. Search for new mechanisms to reduce the cost of digital development \\
\hline & Solving the problem of data duplication. Unstructured data analysis \\
\hline \multirow[b]{4}{*}{$\begin{array}{l}\text { Management Competencies in the } \\
\text { Digital Economy }\end{array}$} & 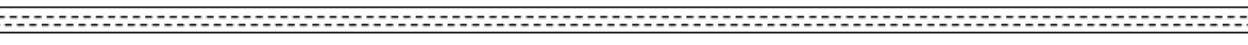 \\
\hline & $\begin{array}{l}\text { Search for new ways of profitability and building the company's system taking into account the risks of cybersecurity, synchronization of big data, } \\
\text { interoperability and problems of legacy systems }\end{array}$ \\
\hline & $\begin{array}{l}\text { Organization of teamwork and the achievement of a synergistic effect through the use of diversity and collective intelligence (including artificial } \\
\text { intelligence systems) }\end{array}$ \\
\hline & $\begin{array}{l}\text { Understanding the development goals of the functional subsystem in accordance with the company's development strategy and the stage of } \\
\text { digital transformation }\end{array}$ \\
\hline & Understanding the correlations between all business processes in the context of ongoing digital transformations \\
\hline & The ability to solve applied problems within the managerial powers of a specific functional subsystem using Industry 4.0 technologies. \\
\hline & Organization and control of work based on modern digital technologies \\
\hline
\end{tabular}

Fig. 6. The second stage of the formation of competencies in the formation of the trajectory of development of traditional and new (digital) competencies

The technologies of studying the disciplines of the educational program involve blended learning with the introduction of online lectures for each discipline. Lectures are combined into training modules. Each discipline consists of training modules. Immersion in the educational process occurs through the development and implementation of tasks using information technology and software products, as well as application packages with a graphical interface.

Figure 7 shows a scattered schedule of the organization of the educational process in digital education, which reflects the six-semester implementation of educational content with a modular study of disciplines. The results of the training of a future specialist in the process of implementing a model of digital and organizational transformation of the educational process should reflect the level of formation of universal, general professional and professional competencies in the areas of relevant competencies.

The formation of universal competencies is determined by the ability to formulate the need for information, create information retrieval strategies, analyze, compare and evaluate the reliability of data sources, look for opportunities for self-development and self-realization in a digital environment. Also, the formation of these competencies is determined by the ability to manage data, information and digital content, to understand digital culture in professional activities.

The formation of general professional competencies is determined by the ability to interact in the information environment through various digital technologies, exchange data, information and digital content through digital technologies, use digital tools to produce resources and knowledge, and introduce digital culture in professional activities.

The formation of professional competencies is determined by the ability to interpret information and digital content, determine the needs for technological and digital solutions, use digital technologies to create innovations, find the creative use of digital technologies, and determine the prospects for the development of digital competencies. 


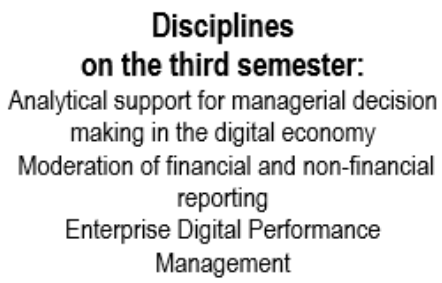

Disciplines on the third semester:

Analytical support for managerial decision making in the digital economy

Moderation of financial and non-financial reporting

Enterprise Digital Performance Management

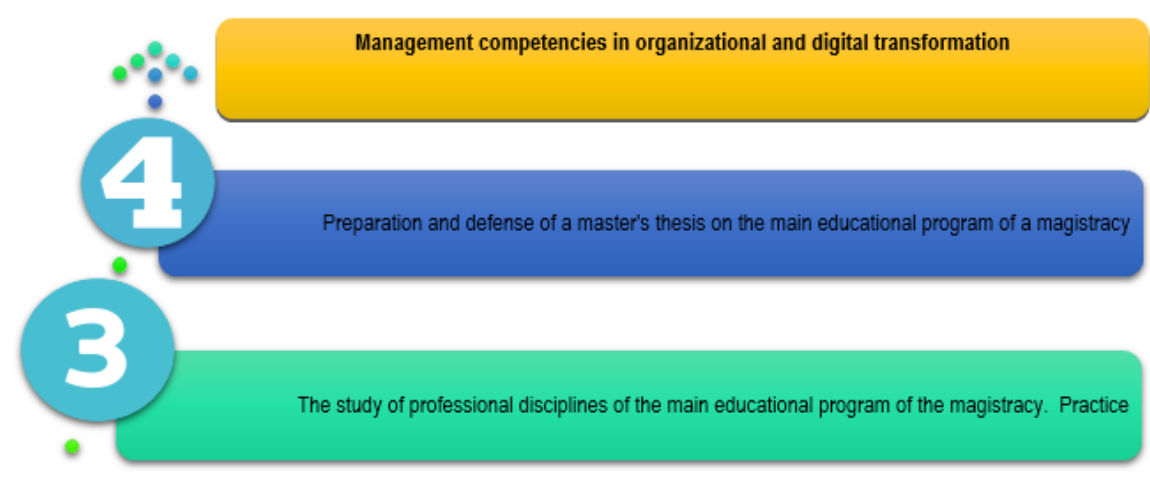

Disciplines

on I and II semesters:

Financial Management Technologies Theory and decision-making methods in the digital economy ERP system

Office technologies as an element of the digital environment in enterprise management

Credit and investment market in the digital economy

Using cloud services in management decision making

Internal Audit and Control in the Digital Economy

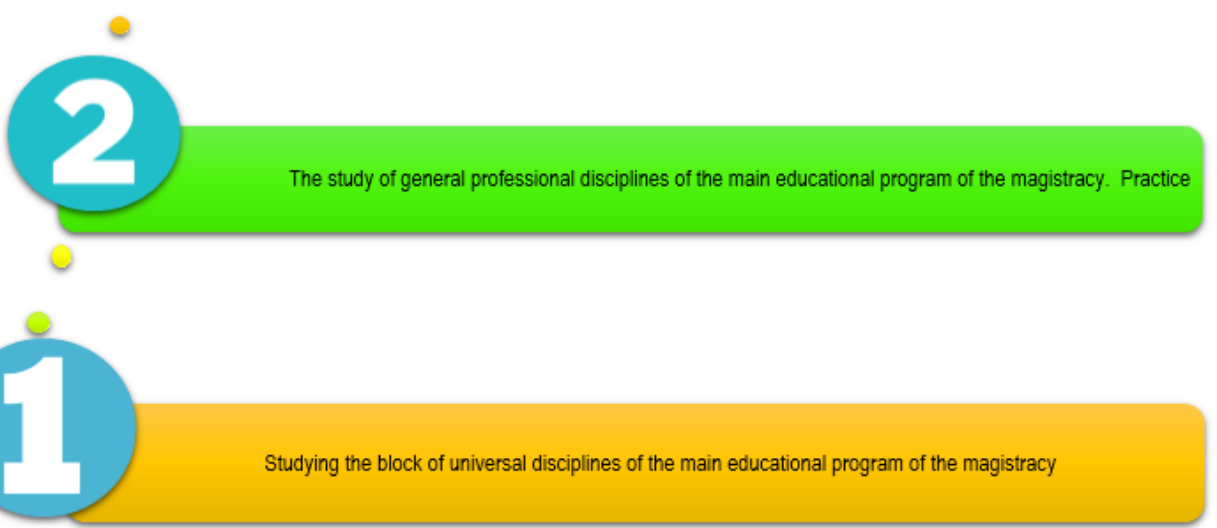

Fig. 7. A dispersed timetable for the organization of the educational process in digital education

\section{DISCUSSION}

Most foreign and Russian scientists and specialists in the field of knowledge and human capital management [5, 6, 7, 8] agree that in the conditions of the fourth industrial revolution, the main factors in creating capital and economic growth of economic systems are human capital (intellectual capital) and digital technology.

It should be agreed with a group of scientists Popkova Elena and Alpidovskaya Marina, who note that in the conditions of the formation of a high-tech society, a person and a technical device are at the center of social interactions that are equipped with artificial intelligence. In these conditions, a person as a source of creating human capital for the economic system should be adapted to the socioeconomic paradigm of the future through digital knowledge and skills and to the digital economy [9].

Many scientific publications $[10,11]$ are devoted to the organizational transformation of managerial education, which is aimed at training new personnel for the digital economy. Many people agree that technologies should be introduced into the educational environment that will allow preparing specialists with competencies in the formation and use of a large data array when making managerial decisions in the professional field and capable of using modern management methods based on information data.

Such an organizational transformation of the educational process will improve the efficiency of human capital management in the economic system. In separate scientific studies $[12,13,14]$ the importance of the knowledge management system as an integral element of human capital management is substantiated, its essence is revealed from the point of view of forming a unified corporate knowledge base and creating conditions for the efficient use of human capital in the digital economy. Moreover, the knowledge management system should be integrated into any economic system and evaluated in terms of its effectiveness [15].

\section{CONCLUSION}

Thus, the model of organizational and digital transformation of the educational process proposed in a scientific publication will improve the efficiency of human capital management based on the formation of digital competencies in the context of structural changes in the economy.

\section{REFERENCES}

[1] E.V. Galaeva The study of human capital in foreign literature: an abstract of the book Horde Nordhog "Human capital in organizations" // Society and Economics. - 1997. - No. 7-8. - S. 244-255.

[2] I.V. Tsapenko The problem of effective reproduction of human capital and investment approaches to it // Innovations. - 2010. - No. 4.

[3] J.H. Bair The state of the product in knowledge management // Journal of Knowledge Management. 1998. No. 2 (2). P. 20-27.

[4] A. D. Marwick Knowledge management technology // IBM systems journal. 2001. No. 40 (4). P. 814-830.

[5] G.S. Becker Human behavior: an economic approach: selected works on economic theory. - M .: SU-HSE, 2003.

[6] C.O. Egbu A conceptual framework for studying knowledge management in projectbased environments // Proceedings of the First International Conference on Postgraduate Research in the Built Environment (University of Salford, UK, 15-16 March 2001) Vol. 10. - P. 186 - 195. 
[7] L.I. Vanchukhina; T.B. Leybert; E.A. Khalikova; A. R. Khalmetov. New Approaches to Formation of Innovational Human Capital as an Element of Institutional Environment // Espacios. - 2018. - №39. - P. $22-32$.

[8] E.G. Popkova, S. Sergi Bruno (2018). Will Industry 4.0 and Other Innovations Impact Russia's Development? In Bruno S. Sergi (Ed.) Exploring the Future of Russia's Economy and Markets: Towards Sustainable Economic Development, Bingley, UK: Emerald Publishing, pp. 51-68.

[9] E.G. Popkova, M. Alpidovskaya. Human and Technological Progress Towards the Socio-Economic Paradigm of the Future // Interdisciplinary Thought of the 21st Century Management, Economics and Law. - DE GRUYTER OLDENBOURG, 2018. - 180 p.

[10] L.V. Averina, E.P. Pecherskaya, O.V. Astafeva. Effective staff training for the contract system in the conditions of the digital economy: Opportunities and limitations // Advances in Intelligent Systems and Computing. - 2020. - № 908. - C. 510-517.
[11] L.I. Vanchukhina, T. B. Leybert, A.M. Rogacheva, Yu.R. Rudneva, E. A. Khalikova. New Model of Managerial Education in Technical University // International Journal of Educational Management. 2019. - №33 (3), C. 511-524.

[12] Andreeva T., Kianto A. Does knowledge management really matter? Linking knowledge management practices, competitiveness and economic performance // Journal of Knowledge Management. 2012. № 16 (4). P. 617-636.

[13] G.L. Adams, B.T. Lamont. Knowledge management systems and developing sustainable competitive advantage // Journal of Knowledge Management. 2003. № 7 (2). C. 142-154.

[14] R. Chapman, M. Magnusson Continuous innovation, performance and knowledge management: an introduction // Knowledge and Process Management. 2006. № 13 (3). C. 129-131.

[15] R.S. Kaplan, D.P. Norton The Balanced Scorecard - Measures then drive Performance // Harvard Business Review. - 1992. - Vol. 70. No. 1. - P. 71-79. 